\title{
Invasive Procedures and Length of Stay among Critically Ill Patients in ICU over Three Years: A Retrospective Study
}

\author{
Mohammad Alnaeem ${ }^{1}{ }^{\circ}$, Alaa Abuatallah² \\ ${ }^{1}$ The University of Jordan, Amman, Jordan \\ ${ }^{2}$ Ministry of Health, Prince Hamzah Hospital, Amman, Jordan \\ Email:mmalnaeem33@gmail.com, alaa.abuatallah@gmail.com
}

How to cite this paper: Alnaeem, M. and Abuatallah, A. (2019) Invasive Procedures and Length of Stay among Critically Ill Patients in ICU over Three Years: A Retrospective Study. Open Journal of Nursing, 9, 765-778.

https://doi.org/10.4236/ojn.2019.97058

Received: June 25, 2019

Accepted: July 27, 2019

Published: July 30, 2019

Copyright $\odot 2019$ by author(s) and Scientific Research Publishing Inc. This work is licensed under the Creative Commons Attribution International License (CC BY 4.0).

http://creativecommons.org/licenses/by/4.0/

(c) (i) Open Access

\begin{abstract}
Introduction: Intensive care unit (ICU) provides advanced specialized medical and nursing care for critically ill patients. Advanced monitoring techniques are needed to prevent physiologic deterioration, while the underlying disease treated and resolved. Frequents invasive procedure and treatment are used and affect the death rate and length of hospitalization. This study aimed to describe the variables associated with critically ill patients and describe the standard invasive procedures or treatments used among patients in ICU. Method: A retrospective comparative study which utilized the ICU electronic database. The data of 446 dead patients who have admitted to ICU between January 2014 and December 2016 as a case of sepsis, heart failure or COPD exacerbation were enrolled. Result: Almost of all patients had received intravenous fluid and vasoactive drugs. The mechanical ventilation support and insertion of the indwelling urethral catheter commonly used among patients with critical illnesses; 78.3\%, 41.3\% respectively. One-third of all sepsis and heart failure patients were received CVC during ICU stay; patients with sepsis illness had less hospital length of stay than patients with heart failure and COPD ( $\mathrm{p}$ 0.05). Also, patients with sepsis illness had less hospital LOS than patients with heart failure and COPD $(\mathrm{p}<0.05)$. There were no significant differences between ICU length of stay based on patients critical illness. Conclusion: We found a reduction in the death number among sepsis, heart failure and COPD patients with move forwards in years, the variety of death rate depends on the type of invasive procedure and treatment performed for each illness, mechanical ventilation support and insertion of indwelling urethral catheter commonly used among patients with critical illnesses.
\end{abstract}

\section{Keywords}

Critical Illness, Intensive Care Unit, Invasive Procedures, Chronic 
Obstructive Pulmonary Disease, Heart Failure, Sepsis, Mortality Rate, Length of Stay

\section{Introduction}

Intensive care unit (ICU) provides advanced specialized medical and nursing care for critically ill patients to support life during a period of life-threatening organ system dysfunction [1]. Recently, the condition of critically ill patients in ICU needs many decisions to rely on the accurate assessment of the hemodynamic status as well as physiological condition to assist in guiding clinical decisions [2] [3] [4]. Therefore, advanced monitoring techniques are needed to prevent physiologic deterioration, while the underlying disease treated and resolved [5]. Progress in technology has influenced the way medical professionals approach hard decision for critically ill patients and their families. Even more, delicate by proposing some interventions that may not be prerequisite [6], the patient severity of illness, time of care demand, and a large amount of physiological, hemodynamic, mechanical ventilation (MV) and laboratory data still considerable challenging in the care of critically ill patients [7].

Despite the multiple complex interventions performed to critically ill patients [8], the mortality rate among critically ill patients in ICU are varied [9]; and the highest compared with other hospital sections [10]. The average mortality rate in ICU patients ranged from $8 \%-19 \%$ in the United States [9], and (19.1\%) in European countries [10]. As well, the most common cause of admission to the ICU in the USA is an acute respiratory failure [11]. It occurred as a consequence of chronic obstructive pulmonary disease (COPD) exacerbations [12]; heart failure (CHF), and sepsis [13].

COPD is the crucial third cause of death [14], with a global mortality rate of more than 3 million, which represents $6 \%$ of all deaths worldwide in 2012 [15]. Among US patients, it is the fourth cause of death [16]. Furthermore, there was over 5 million Americans have diagnosed with Congestive Heart failure (CHF). Around 365,000 of them admitted to ICU, and about 80,000 patients required MV [17], in USA the mortality rate among heart failure in ICU was $4.3 \%$ whereas 30 -day mortality rate was $10.7 \%$ [18]. Also, the sepsis account about $20 \%$ of all ICU admission internationally [19]. Sepsis affects around 1.5 million individuals in the US annually, causing the death of 250,000 individuals and being responsible for one out of every three hospital deaths [20].

In particular, two studies conducted in the middle east country concluded that the mortality rate in ICU (over two weeks) was only 6.4\% [21]. As similar to other study revealed that the hospital mortality of heart failure was $5.3 \%$, and reached 7.5\% 30 days after hospital discharge [22]. However, there is limited data about the mortality rate of sepsis, heart failure, and COPD Jordanian patients in ICUs; just general information about the prevalence of these critical illnesses 
[23]. The mortality rate among patients with critical disease considers an alarm to healthcare providers to investigate those patient-based trends and practices in the last days of life. Thus, it is essential to explore the most typical devices and practices used in ICU in recent days of life. Few studies have examined matters around the method among critically ill patients in Jordan in the last days, especially in ICU.

Up to our knowledge, there are no studies that have described characteristics of ICU mortality in patients with a critical illness like COPD, heart failure, sepsis. Therefore, we reviewed the ICU database and hospital records for patients with COPD, heart failure, and sepsis who died in ICU over four years at the governmental hospital.

\section{Aim}

We aim to describe the variables associated with critically ill patients, estimate the death rate, and describe the standard invasive procedures or treatments used among patients in ICU. As well as, we evaluate the differences between this critical illness in term of socio-demographic data and the length of hospital and ICU stay.

\section{Research Questions}

1) What are the characteristics of critically ill patients who deceased in ICU?

2) What are the ICU and hospital length of stay and the estimated death rate for each of critically ill patients who died in ICU?

3) Is there are a difference between critically ill patients and the standard invasive procedures and treatments used in ICU?

4) Are the demographic variables and the length of stay associated with critical illnesses?

\section{Materials and Methods}

\subsection{Design and Setting}

This study is a retrospective comparative study which utilized the ICU electronic database at Prince Hamza Hospital in Jordan. This hospital was one of the primary governmental institutions in Jordan with numerous specialties and served different patients conditions. The closed medical/surgical ICU in this hospital comprises a 12-bed that annually provide services for about 600 critically ill patients with varying conditions with high quality of care [24].

\subsection{Sample and Sampling}

All patients ( $\geq 16 \mathrm{yr}$ old) who died in the ICU between January 2014 and December 2016 and have admitted as a case of sepsis, heart failure or COPD exacerbation were enrolled. The outcome of interest was the ICU mortality among critically ill patients, which determined by using the ICU database to identify patients admitted to the ICU. The baseline patients' characteristics and demo- 
graphics recorded. Also, clinical data such as Length of ICU and hospital stay, co-morbidities, invasive procedures, and treatments provided for those patients in last ICU admission were recognized. The records of 1345 patients who died in the selected period, only 446 patients had the fulfilled details and met the study inclusion criteria; accordingly utilized in the analysis. The patients who admitted to ICU for less than four hours or have diagnosed with more one critical illness; were excluded from the study.

\subsection{Data Collection Method}

The ICU database includes information for all patients to die in the ICU. All the demographics and clinical characteristics data were collected retrospectively from each patient's electronic medical record. A collection tool was designed to assemble the data by the authors based on the literature review and the opinion of two experts. The questionnaire was structured and consisted of two parts that filled for each patient (Appendix A). First part obtained the demographic data (Age, gender, Nationality, and death year). Second part handled the clinical characteristics (length of hospital and ICU stay, received invasive procedures in ICU such as Mechanical ventilator, Central Venous Catheter, Indwelling Urethral Catheter, Vasoactive drugs, Antibiotic, and Intravenous Fluids). Data collected through the authors who had at least three years of experiences in critical care units as well had a master degree in nursing care. Full description for the research project was performed once before starting the data collection process, including the required details of all concepts and data collection procedures. The time of data collection extended to six months.

\subsection{Ethical Consideration}

The study approved by the institutional review board of the selected hospital. A waiver of informed consent from patients for retrospective was used to data collection and analysis.

\subsection{Data Analysis}

The statistical analysis performed with SPSS, version 22.0. Descriptive and inferential analyses of the socio-demographic and significant study variables conducted. For continuous variables, the mean and standard deviation were described and rounded to two decimal. Categorical variables presented as number and percentages. The chi-square test was conducted to compare the differences in invasive procedures and treatments for the sepsis, heart failure, and COPD patients groups. Moreover, the ANOVA test used to evaluate the association between demographic variables and the length of hospital and ICU stay in terms of the critical illnesses. The requisite significance level set at a P-value $<0.05$.

\section{Results}

Descriptive statistics for the study cases provided in Table 1 . The percentage of 
Table 1. Descriptive statistics for the study variables.

\begin{tabular}{|c|c|c|c|c|}
\hline \multirow[b]{2}{*}{ Characteristics } & \multicolumn{3}{|c|}{ Frequency (\%) } & \multirow[b]{2}{*}{ Total $(\mathrm{N}=446)$} \\
\hline & $\begin{array}{c}\text { Sepsis } \\
(\mathrm{N}=149)\end{array}$ & $\begin{array}{l}\text { Heart Failure } \\
\qquad(\mathrm{N}=148)\end{array}$ & $\begin{array}{c}\text { COPD } \\
(\mathrm{N}=149)\end{array}$ & \\
\hline \multicolumn{5}{|l|}{ Year of Death } \\
\hline 2014 & $54(36.3 \%)$ & $48(32.4 \%)$ & $51(34.2 \%)$ & 153 \\
\hline 2015 & $44(29.5 \%)$ & $68(46 \%)$ & $52(34.9 \%)$ & 164 \\
\hline 2016 & $51(34.2 \%)$ & $32(21.6 \%)$ & $46(30.9 \%)$ & 129 \\
\hline \multicolumn{5}{|l|}{ Patients gender } \\
\hline Male & $73(49 \%)$ & $75(50.7 \%)$ & $84(56.4 \%)$ & 232 \\
\hline Female & $76(51 \%)$ & $73(49.3 \%)$ & $65(43.6 \%)$ & 214 \\
\hline \multicolumn{5}{|l|}{ Co-morbidities* } \\
\hline Diabetes & $78(52.3 \%)$ & $94(63.5 \%)$ & $76(51 \%)$ & 248 \\
\hline Hypertension & $97(65.1 \%)$ & $112(75.7 \%)$ & $94(63.1 \%)$ & 303 \\
\hline Neurological disorder & $68(45.6 \%)$ & $23(15.5 \%)$ & $36(24.2 \%)$ & 127 \\
\hline Other & $44(29.5 \%)$ & $41(27.7 \%)$ & $39(26.2 \%)$ & 124 \\
\hline \multicolumn{5}{|l|}{ Admission source } \\
\hline Hospital wards & $62(41.6 \%)$ & $88(59.5 \%)$ & $91(61.1 \%)$ & 241 \\
\hline Emergency department & $74(49.7 \%)$ & $49(33.1 \%)$ & $45(30.2 \%)$ & 168 \\
\hline Other hospitals & $13(8.7 \%)$ & $11(7.4 \%)$ & $13(8.7 \%)$ & 37 \\
\hline \multicolumn{5}{|l|}{$\begin{array}{l}\text { Times of ICU admission } \\
\text { during hospitalization }\end{array}$} \\
\hline Once & $144(96.6 \%)$ & $132(89.2 \%)$ & $146(98 \%)$ & 422 \\
\hline More than one & $5(3.4 \%)$ & $16(10.8 \%)$ & $3(2 \%)$ & 24 \\
\hline
\end{tabular}

Note: ${ }^{*}$ more than one response was acceptable.

death among all critically ill patients slightly declined over three years. With the advance in years, patients with sepsis in ICU die more than heart failure and COPD patients; while, the lowest death rate was among heart failure patients. More males than females have died in the ICU among patients with COPD and heart failure; $(56.4 \%, 50.7 \%)$ respectively. More than $50 \%$ of critically ill patients had co-morbidities, and the highest patients in ICU with more than one morbidity was the sepsis patients (64.4\%). Hypertension and diabetes are the frequent co-morbidities among the patients who die in ICU with heart failure, sepsis, and COPD correspondingly. The majority of the patients who died in the ICUs transferred from the same hospital (54\%), with COPD (61.1\%) and heart failure (59.5\%) illness. Around half of the patients who died in the ICUs were free from other co-morbidities. Only (5.4\%) were admitted to ICU more than one time during hospitalization.

Table 2 presents the ICU and hospital mean of hourly length of stay (LOS); besides, the death rate per three critical illnesses in Jordanian's hospital during the years 2014 to 2016. Our findings revealed that the patient with sepsis is the most patients need a long period in ICU while they stay in hospital short time compared with other illnesses. Patients with heart failure and COPD need ex- 
tended hospitalization than sepsis patients. As well, the lowest death rate in ICU was among patients with COPD and heart failure patients, while the highest was in patients with sepsis (Table 2).

Table 3 shows the percentage of the regular invasive procedures and treatment provided during hospitalization per chronic diseases for patients in ICU. We found that mechanical ventilation support and insertion of the indwelling urethral catheter commonly used among patients with sepsis, heart failure, and COPD; 78.3\%, 41.3\% respectively. Most of those patients had received intravenous fluid (95.7\%) and vasoactive drugs (90.1\%). One-third of all sepsis patients was received CVC during ICU stay. Furthermore, regarding the invasive procedure, all critical illnesses seem to be related to necessary ventilation support ( $\mathrm{p}<$ $0.01)$. Regard the treatments used in ICU, an association between these diseases (sepsis, heart failure, COPD) and administration of intravenous fluid, vasoactive infusion, and antibiotics were observed significantly (Table 3 ).

Patients with sepsis illness had less hospital LOS than patients with heart failure and COPD $(\mathrm{p}<0.05)$. Patients in ICU with sepsis were older than patients with COPD $(\mathrm{p}<0.01)$; and patients who die in ICU with heart failure illness was older than patients with COPD $(p=0.034)$. There were no significant differences between ICU length of stay based on patients' critical illnesses (Table 4).

Table 2. Length of stay and death rate per chronic disease for patients in ICUs in Jordan.

\begin{tabular}{cccccc}
\hline Critical illness & $\begin{array}{c}\text { Mean Hospital LOS } \\
(\text { SD })\end{array}$ & $\begin{array}{c}\text { Mean ICU-LOS } \\
(\text { SD })\end{array}$ & $\begin{array}{c}\text { Number of } \\
\text { death }\end{array}$ & $\begin{array}{c}\text { Number of } \\
\text { survived }\end{array}$ & Death rate \\
\hline Sepsis & $39.22(86.8)$ & $131.83(178.3)$ & 149 & 10 & 0.21 \\
Heart failure & $64.51(105.9)$ & $92.88(120.8)$ & 148 & 6 & 0.11 \\
COPD & $61.48(103.8)$ & $118.1(135.1)$ & 149 & 8 & 0.10 \\
\hline
\end{tabular}

Table 3. Invasive procedures and treatments during hospitalization per chronic disease for patients in ICUs in Jordan.

\begin{tabular}{|c|c|c|c|c|c|}
\hline Invasive procedures & $\begin{array}{l}\text { Sepsis } \\
\mathrm{N}(\%)\end{array}$ & $\begin{array}{c}\text { Heart Failure } \\
\text { N (\%) }\end{array}$ & $\begin{array}{l}\text { COPD } \\
\mathrm{N}(\%)\end{array}$ & $\mathrm{x}^{2}$ & $\mathrm{P}$ value \\
\hline Mechanical ventilation & $103(69.1)$ & $119(80.4)$ & $126(84.6)$ & 11.1 & $0.004^{\star \star}$ \\
\hline Central venous catheter & $48(32.2)$ & $47(31.8)$ & $34(22.8)$ & 4.06 & 0.131 \\
\hline Chest tube & $1(0.67)$ & $47(31.8)$ & $34(22.8)$ & 1.01 & 0.603 \\
\hline Indwelling urethral catheter & $66(44.3)$ & $62(41.9)$ & $56(37.6)$ & 1.42 & 0.491 \\
\hline \multicolumn{6}{|c|}{ Treatment } \\
\hline Antibiotic & $133(89.3)$ & $110(74.3)$ & $131(87.9)$ & 15.7 & $0.001^{\star *}$ \\
\hline Fluid resuscitation & $148(99.3)$ & $136(91.9)$ & $143(96)$ & 10.1 & $0.006^{\star *}$ \\
\hline Vasoactive drugs & $134(89.9)$ & $127(85.8)$ & 141(94.6) & 6.51 & $0.039^{*}$ \\
\hline
\end{tabular}

Note: ${ }^{*} \mathrm{p}<0.05,{ }^{* *} \mathrm{p}<00.1$ 
Table 4. ANOVA test with post hoc for hospital LOS, ICU LOS, and age with critical diseases.

\begin{tabular}{|c|c|c|c|c|}
\hline \multirow{2}{*}{ Groups } & \multicolumn{3}{|c|}{ Dependent variables } & \multirow{2}{*}{ LSD Post hoc } \\
\hline & Mean & Standard deviation & F statistics & \\
\hline \multicolumn{5}{|c|}{ Age } \\
\hline 1) Sepsis & 67.93 & 19.88 & & \\
\hline 2) Heart failure & 67.34 & 12.88 & $7.907^{* *}$ & $1>3^{* *} ; 2>3^{* *}$ \\
\hline 3) $\mathrm{COPD}$ & 60.69 & 18.73 & & \\
\hline \multicolumn{5}{|c|}{ ICU length of stay/hours } \\
\hline 1) Sepsis & 131.83 & 178.33 & & \\
\hline 2) Heart failure & 92.88 & 120.78 & 2.686 & \\
\hline 3) $\mathrm{COPD}$ & 118.10 & 135.10 & & \\
\hline \multicolumn{5}{|c|}{ Hospital length of stay/hours } \\
\hline 1) Sepsis & 39.22 & 86.833 & & \\
\hline 2) Heart failure & 64.51 & 105.99 & $2.882^{*}$ & $2>1^{\star} ; 3>1^{\star}$ \\
\hline 3) $\mathrm{COPD}$ & 61.48 & 103.75 & & \\
\hline
\end{tabular}

Note: ${ }^{*} \mathrm{p}<0.05,{ }^{* *} \mathrm{p}<0.01$.

\section{Discussion}

This retrospective study among patients with sepsis, heart failure, and COPD who die between 2014 to 2016 in the governmental hospital. Important information about the mortality of ICU patients with critically ill can also guide decisions regarding the burden of treatment and success rates [25]. In our study, we found a lowering in the death number among critically ill patients with move forwards in years. As well, the mortality among male and female was comparable in patients with sepsis and heart failure.

The length of stay and death rate varied in our patients. The septic patients need a more extended period in the ICU and have the highest death rate when compared with other diseases. When comparing these findings with other studies, we found a parallel result [26]. Also, the patients of heart failure and COPD need more extended hospitalization and lower death rate in ICU when compared with sepsis patient. These findings have described in previous studies [27] [28], found that one-third of 119 COPD patients who admitted to ICU mechanically ventilated for a median duration of 3 days and nine days in the hospital.

Critically ill patients who admitted to the ICU have to be monitored [29]. The severity and complexity of the critically ill patients determine the need for performed invasive procedures [30]. Previous studies showed that management of critically ill patient through invasive procedures like central venous catheter (CVC) or mechanical ventilation support; improved oxygen delivery and decreased the mortality [30]. CVC is the standard invasive procedure performed in 
the ICU, and in the United States, more than five million CVC inserted every year [31]. The indications for CVC insertion, which are when vasoactive drugs infused [32] or to measure the central venous pressure (CVP) [29]. Additionally, CVC represents the frequent used to guide fluid resuscitation in critically ill patients [19] [33].

Our study also indicates the importance of these invasive procedures for critically ill patients in ICU rather than focusing on one critical illness. Most of all patients had received intravenous fluid and vasoactive drugs, and one-third of all sepsis and heart failure patients were received CVC during ICU stay. However, the death rate was higher among sepsis even they used CVC commonly; this finding inconsistent with the previous study [34]. A prospective study conducted over seven years among 6597 patients with heart failure revealed that 16 patients of 102 deceased patients were used vasoactive drugs in their last three days [35].

Furthermore, we found that mechanical ventilation support and insertion of an indwelling urethral catheter (IUC) commonly used among patients with critical illnesses; $78.3 \%, 41.3 \%$ respectively. IUC routinely inserted to monitor urine output in patients with acute heart failure, is associated with longer hospitalization length when compared with patients without IUC [36]. Additionally, our results revealed that all critical diseases related with the necessary ventilation support and invasive procedure. These procedures consider as a life-saving intervention for respiratory failure secondary to decompensated heart failure [37] [38], and COPD patient with moderate to severe aggravating [14]. The study [27] found that patients who admitted to ICU with sepsis (41.8\%) and COPD (5.4\%) were commonly received MV. While the COPD patients, after supported with MV, found to be negatively related to mortality. As well, [39] stated that around $26.7 \%$ of COPD patient who required mechanical ventilation died in ICU.

A congruent between previous studies and our finding in regard the treatments such as intravenous fluid, vasoactive drugs, and Antibiotic used in ICU among critically ill patients. These treatments attributed to prolonged invasive procedures use, as well as more days spent in ICU and hospitalization. Several studies support our findings; fluid resuscitation improves organ perfusion and impacts survival in sepsis patients [40] [41]. As well, in another study about the septic patient in ICU, about $83.9 \%$ of patients needed mechanical ventilation, (27.7\%) vasoactive drugs infusion and (39.5\%) died, with a range of length of stay 10 - 43 days [39]. Also, appropriate antibiotics recommended for a patient in ICU with sepsis [19], and it could be reduced the mortality rate among ICU patients [42]. An agreement with our finding found that antibiotic treatment associated with lower ICU and hospital mortality [26].

Our findings concur with previous studies regarding the age of critically ill patients who die in ICU. Patients in ICU with sepsis (68 years) was older than patients with COPD (60 years), and patients who die in ICU with heart failure illness (67 years) was older than patients with COPD. Comparable findings concluded in other studies; in a prospective cohort study, the mean age of among patients who required mechanical ventilation in ICU was 57 years [27]. Also, among 
COPD patients in another study, the mean age of patients in ICU was 72 years [28]. While in a retrospective study to predict mortality in CICU, the mean age of patients with the cardiac condition who stay in ICU 3 days was 70 years [43].

Moreover, our finding indicates that the chest tube was inserted more frequent among heart failure and COPD patients. The justification may be used to manage tension secondary spontaneous pneumothorax as a complication of COPD [44]. Some researcher described chest tubes as a life-saving device [45] [46], and represents a factor of mortality [47]. As well as, it considered a cause for prolonged hospital stay; especially among COPD patients [47].

Our study provides large scale comparative data in critically ill patients; unfortunately, it has several limitations that should consider when interpreting the data. The survey conducted in one governmental hospital, which lead to focus on one type of invasive procedure and treatment provided for patients, this limits the generalizability. Also, the study did not measure the co-morbidity factors that may affect the study variables. Conducting a prospective study with a focus on the APACHE and SOFA score with a larger population is needed.

\section{Key Points for Practice and Research}

The results of this study have the following implications for nursing practice and research. Regarding the clinical, nurses who provide care for critically ill patients in ICU spend more time with patients than other health care providers. So, nurses have to prepare with an evidence-based practice that enables them to advocate patient rights regarding the required invasive procedures and treatments. Besides using the accurate assessment of patients statues necessary to improve the patients' outcomes. On the research track, the impact of invasive procedures and treatments in ICU needs to evaluate its effectiveness and feasibility in a clinical practice setting. Another broader longitudinal prospective study that measures the predictors of mortality rate among critically ill patients is required .

\section{Conclusion}

This study reveals important information about critically ill patients admitted to ICU, and the invasive procedure and treatment (CVP, MV, IUC, chest tube, antibiotics, vasopressor, fluid resuscitation). As well, it is the effect on many related outcomes, include death rate, length of the hospital, and ICU stay. We found that the number of death among critically ill patients increases with move forwards in years. The variety of death rate depends on the type of invasive procedure and treatment performed for each illness, mechanical ventilation support, and insertion of the indwelling urethral catheter commonly used among patients with critical diseases.

\section{Acknowledgements}

The authors are grateful to the Prince Hamzah Hospital for partially funding this study. 


\section{Author Contributions}

All authors have agreed on the final version, and substantial contributions to terms and design, acquisition of data, or analysis and interpretation of data.

\section{Conflicts of Interest}

The authors declare no conflicts of interest regarding the publication of this paper.

\section{References}

[1] Marshall, J.C., Bosco, L., Adhikari, N.K., Connolly, B., Diaz, J.V., Dorman, T., Vincent, J.L., et al. (2017) What Is an Intensive Care Unit? A Report of the Task Force of the World Federation of Societies of Intensive and Critical Care Medicine. Journal of Critical Care, 37, 270-276. https://doi.org/10.1016/j.jcrc.2016.07.015

[2] Potter, B.J., Deverenne, B., Doucette, S., Fergusson, D., Magder, S. and Canadian Critical Care Trials Group (2013) Cardiac Output Responses in a Flow-Driven Protocol of Resuscitation Following Cardiac Surgery. Journal of Critical Care, 28, 265-269. https://doi.org/10.1016/j.jcrc.2012.09.008

[3] Perel, A., Saugel, B., Teboul, J.L., Malbrain, M.L., Belda, F.J., Fernández-Mondéjar, E., Maggiorini, M., et al. (2016) The Effects of Advanced Monitoring on Hemodynamic Management in Critically Ill Patients: A Pre and Post Questionnaire Study. Journal of Clinical Monitoring and Computing, 30, 511-518. https://doi.org/10.1007/s10877-015-9811-7

[4] Teboul, J.L., Saugel, B., Cecconi, M., De Backer, D., Hofer, C.K., Monnet, X., Squara, P., et al. (2016) Less Invasive Hemodynamic Monitoring in Critically Ill Patients. Intensive Care Medicine, 42, 1350-1359. https://doi.org/10.1007/s00134-016-4375-7

[5] Thimmapur, R.M., Raj, P., Raju, B., Kanmani, T.R. and Reddy, N.K. (2018) Caregivers Satisfaction with Intensive Care Unit Services in Tertiary Care Hospital. International Journal of Critical Illness and Injury Science, 8, 184. https://doi.org/10.4103/IJCIIS.IJCIIS $25 \quad 18$

[6] Eues, S.K. (2007) End-of-Life Care: Improving the Quality of Life at the End of Life. Professional Case Management, 12, 339-344. https://doi.org/10.1097/01.PCAMA.0000300408.00325.1c

[7] Sevransky, J.E., Checkley, W., Herrera, P., Pickering, B.W., Barr, J., Brown, S.M., Girard, T.D., et al. (2015) Protocols and Hospital Mortality in Critically Ill Patients: The United States Critical Illness and Injury Trials Group Critical Illness Outcomes Study. Critical Care Medicine, 43, 2076. https://doi.org/10.1097/CCM.0000000000001157

[8] Siddiqui, S. (2015) Mortality Profile across Our Intensive Care Units: A 5-Year Database Report from a Singapore Restructured Hospital. Indian Journal of Critical Care Medicine: Peer-Reviewed, Official Publication of Indian Society of Critical Care Medicine, 19, 726. https://doi.org/10.4103/0972-5229.171401

[9] Mukhopadhyay, A., Tai, B.C., See, K.C., Ng, W.Y., Lim, T.K., Onsiong, S., Phua, J., et al. (2014) Risk Factors for Hospital and Long-Term Mortality of Critically Ill Elderly Patients Admitted to an Intensive Care Unit. BioMed Research International, 2014, Article ID: 960575. https://doi.org/10.1155/2014/960575

[10] Capuzzo, M., Volta, C.A., Tassinati, T., Moreno, R.P., Valentin, A., Guidet, B., Poncet, A., et al. (2014) Hospital Mortality of Adults Admitted to Intensive Care 
Units in Hospitals with and without Intermediate Care Units: A Multicentre European Cohort Study. Critical Care, 18, 551.

https://doi.org/10.1186/s13054-014-0551-8

[11] Signoff, E.D., Adams, J.Y. and Kuhn, B.T. (2017) Initiation of Mechanical Ventilation in Patients with Decompensated Respiratory Failure. Hospital Medicine Clinics, 6, 503-516. https://doi.org/10.1016/j.ehmc.2017.05.006

[12] Hajizadeh, N., Goldfeld, K. and Crothers, K. (2015) What Happens to Patients with COPD with Long-Term Oxygen Treatment Who Receive Mechanical Ventilation for COPD Exacerbation? A 1-Year Retrospective Follow-Up Study. Thorax, 70, 294-296. https://doi.org/10.1136/thoraxinl-2014-205248

[13] Kaukonen, K.M., Bailey, M., Suzuki, S., Pilcher, D. and Bellomo, R. (2014) Mortality Related to Severe Sepsis and Septic Shock among Critically Ill Patients in Australia and New Zealand, 2000-2012. JAMA, 311, 1308-1316.

https://doi.org/10.1001/jama.2014.2637

[14] Dixit, D., Bridgeman, M.B., Andrews, L.B., Narayanan, N., Radbel, J., Parikh, A. and Sunderram, J. (2015) Acute Exacerbations of Chronic Obstructive Pulmonary Disease: Diagnosis, Management, and Prevention in Critically Ill Patients. Pharmacotherapy: The Journal of Human Pharmacology and Drug Therapy, 35, 631-648. https://doi.org/10.1002/phar.1599

[15] Faes, K., De Frène, V., Cohen, J. and Annemans, L. (2016) Resource Use and Health Care Costs of COPD Patients at the End of Life: A Systematic Review. Journal of Pain and Symptom Management, 52, 588-599. https://doi.org/10.1016/j.jpainsymman.2016.04.007

[16] Chou, W.C., Lai, Y.T. and Hung, Y.S. (2013) Comparing End-of-Life Care in Hospitalized Patients with Chronic Obstructive Pulmonary Disease with and without Palliative Care in Taiwan. Journal of Research in Medical Sciences: The Official Journal of Isfahan University of Medical Sciences, 18, 594-600.

[17] Barrett, M.L., Smith, M.W., Elixhauser, A., Honigman, L.S. and Pines, J.M. (2011) Utilization of Intensive Care Services.

http://www.hcup-us.ahrq.gov/reports/statbriefs/sb185-Hospital-Intensive-Care-Uni ts-2011.pdf

[18] Bueno, H., Ross, J.S., Wang, Y., Chen, J., Vidán, M.T., Normand, S.L.T., Kosiborod, M., et al. (2010) Trends in Length of Stay and Short-Term Outcomes among Medicare Patients Hospitalized for Heart Failure, 1993-2006. JAMA, 303, 2141-2147. https://doi.org/10.1001/jama.2010.748

[19] Dellinger, R.P., Levy, M.M., Rhodes, A., Annane, D., Gerlach, H., Opal, S.M., Osborn, T.M., et al. (2013) Surviving Sepsis Campaign: International Guidelines for the Management of Severe Sepsis and Septic Shock, 2012. Intensive Care Medicine, 39, 165-228. https://doi.org/10.1007/s00134-012-2769-8

[20] Center for Disease Control and Prevention (CDC) (2017) Making Health Care Safer: Think Sepsis. https://www.cdc.gov/vitalsigns/pdf/2016-08-vitalsigns.pdf

[21] Al-Omari, A., Abdelwahed, H.S. and Alansari, M.A. (2015) Critical Care Service in Saudi Arabia. Saudi Medical Journal, 36, 759.

https://doi.org/10.15537/smj.2015.6.11204

[22] AlHabib, K.F., Elasfar, A.A., AlBackr, H., AlFaleh, H., Hersi, A., AlShaer, F., Mimish, L., et al. (2011) Design and Preliminary Results of the Heart Function Assessment Registry Trial in Saudi Arabia (HEARTS) in Patients with Acute and Chronic Heart Failure. European Journal of Heart Failure, 13, 1178-1184. https://doi.org/10.1093/eurjhf/hfr111 
[23] Al Omari, M., Khassawneh, B.Y., Khader, Y., Dauod, A.S. and Bergus, G. (2014) Prevalence of Chronic Obstructive Pulmonary Disease among Adult Male Cigarettes Smokers: A Community-Based Study in Jordan. International Journal of Chronic Obstructive Pulmonary Disease, 9, 753. https://doi.org/10.2147/COPD.S62898

[24] Ministry of Health (2017) Mortality Data in Jordan, 2013. http://www.moh.gov.jo/Pages/viewpage.aspx?pageID $=248$

[25] Ghassemi, M., Celi, L.A. and Stones, D.J. (2015) State of the Art Review: The Data Revolution in Critical Care. Critical Care, 19, 118. https://doi.org/10.1186/s13054-015-0801-4

[26] Ferrer, R., Martin-Loeches, I., Phillips, G., Osborn, T.M., Townsend, S., Dellinger, R.P., Levy, M.M., et al. (2014) Empiric Antibiotic Treatment Reduces Mortality in Severe Sepsis and Septic Shock from the First Hour: Results from a Guideline-Based Performance Improvement Program. Critical Care Medicine, 42, 1749-1755. https://doi.org/10.1097/CCM.0000000000000330

[27] Fialkow, L., Farenzena, M., Wawrzeniak, I.C., Brauner, J.S., Vieira, S.R.R., Vigo, A. and Bozzetti, M.C. (2016) Mechanical Ventilation in Patients in the Intensive Care Unit of a General University Hospital in Southern Brazil: An Epidemiological Study. Clinics, 71, 144-151. https://doi.org/10.6061/clinics/2016(03)05

[28] Alaithan, A.M., Memon, J.I., Rehmani, R.S., Qureshi, A.A. and Salam, A. (2012) Chronic Obstructive Pulmonary Disease: Hospital and Intensive Care Unit Outcomes in the Kingdom of Saudi Arabia. International Journal of Chronic Obstructive Pulmonary Disease, 7, 819-823. https://doi.org/10.2147/COPD.S37611

[29] Huygh, J., Peeters, Y., Bernards, J. and Malbrain, M.L. (2016) Hemodynamic Monitoring in the Critically Ill: An Overview of Current Cardiac Output Monitoring Methods. F1000Research, 5, 2855. https://doi.org/10.12688/f1000research.8991.1

[30] Kipnis, E., Ramsingh, D., Bhargava, M., Dincer, E., Cannesson, M., Broccard, A., Thibault, R., et al. (2012) Monitoring in Intensive Care. Critical Care Research and Practice, 2012, Article ID: 473507. https://doi.org/10.1155/2012/473507

[31] Phua, G.C. and Wahidi, M.M. (2009) ICU Procedures of the Critically Ill. Respirology, 14, 1092-1097. https://doi.org/10.1111/j.1440-1843.2009.01643.x

[32] Pinsky, M.R., Kellum, J.A. and Bellomo, R. (2014) Central Venous Pressure Is a Stopping Rule, Not a Target of Fluid Resuscitation. Critical Care and Resuscitation, $16,245$.

[33] Cecconi, M., Hofer, C., Teboul, J.L., Pettila, V., Wilkman, E., Molnar, Z., Sander, M., et al. (2015) Fluid Challenges in Intensive Care: The FENICE Study. Intensive Care Medicine, 41, 1529-1537. https://doi.org/10.1007/s00134-015-3850-X

[34] Walkey, A.J., Soylemez-Wiener, R. and Lindenauer, P.K. (2013) Utilization Patterns and Outcomes Associated with the Central Venous Catheter in Septic Shock: A Population-Based Study. Critical Care Medicine, 41, 1450. https://doi.org/10.1097/CCM.0b013e31827caa89

[35] Jacob, J., Miró, Ò., Herrero, P., Martín-Sánchez, F.J., Gil, V., Tost, J., Llorens, P., et al. (2016) Predicting Short-Term Mortality in Patients with Acute Exacerbation of Chronic Heart Failure: The EAHFE-3D Scale. Medicine Intensive (English Edition), 40, 348-355. https://doi.org/10.1016/j.medine.2015.07.004

[36] Aoki, T. (2018) Appropriate Use of Urinary Catheter in Acute Heart Failure Patients. Circulation Journal, 82, 1505-1506. https://doi.org/10.1253/circj.CJ-18-0447

[37] Kuhn, B., Bradley, L., Dempsey, T., Puro, A. and Adams, J. (2016) Management of 
Mechanical Ventilation in Decompensated Heart Failure. Journal of Cardiovascular Development and Disease, 3, 33. https://doi.org/10.3390/jcdd3040033

[38] Wiesen, J., Ornstein, M., Tonelli, A.R., Menon, V. and Ashton, R.W. (2013) State of the Evidence: Mechanical Ventilation with PEEP in Patients with Cardiogenic Shock. Heart, 99, 1812-1817. https://doi.org/10.1136/heartjnl-2013-303642

[39] Quenot, J.P., Binquet, C., Kara, F., Martinet, O., Ganster, F., Navellou, J.C., Perez, P., et al. (2013) The Epidemiology of Septic Shock in French Intensive Care Units: The Prospective Multicenter Cohort EPISS Study. Critical Care, 17, R65. https://doi.org/10.1186/cc12598

[40] Boyd, J.H., Forbes, J., Nakada, T.A., Walley, K.R. and Russell, J.A. (2011) Fluid Resuscitation in Septic Shock: A Positive Fluid Balance and Elevated Central Venous Pressure Are Associated with Increased Mortality. Critical Care Medicine, 39, 259-265. https://doi.org/10.1097/CCM.0b013e3181feeb15

[41] Byrne, L. and Van Haren, F. (2017) Fluid Resuscitation in Human Sepsis: Time to Rewrite History? Annals of Intensive Care, 7, 4. https://doi.org/10.1186/s13613-016-0231-8

[42] Gaieski, D.F., Mikkelsen, M.E., Band, R.A., Pines, J.M., Massone, R., Furia, F.F., Goyal, M., et al. (2010) Impact of Time to Antibiotics on Survival in Patients with Severe Sepsis or Septic Shock in Whom Early Goal-Directed Therapy Was Initiated in the Emergency Department. Critical Care Medicine, 38, 1045-1053. https://doi.org/10.1097/CCM.0b013e3181cc4824

[43] Jentzer, J.C., Bennett, C., Wiley, B.M., Murphree, D.H., Keegan, M.T., Gajic, O., Barsness, G.W., et al. (2018) Predictive Value of the Sequential Organ Failure Assessment Score for Mortality in a Contemporary Cardiac Intensive Care Unit Population. Journal of the American Heart Association, 7, e008169. https://doi.org/10.1161/JAHA.117.008169

[44] Novakov, I. and Shterev, F. (2018) Management of Secondary Tension Pneumothorax as a Complication of Chronic Obstructive Pulmonary Disease: Self-Experience Study. European Respiratory Journal, 52, PA2578. https://doi.org/10.1183/13993003.congress-2018.PA2578

[45] Kwiatt, M., Tarbox, A., Seamon, M.J., Swaroop, M., Cipolla, J., Allen, C., Galwankar, S., et al. (2014) Thoracostomy Tubes: A Comprehensive Review of Complications and Related Topics. International Journal of Critical Illness and Injury Science, 4, 143. https://doi.org/10.4103/2229-5151.134182

[46] Hadzhiminev, V., Kalacheva, K., Batashki, A., Uchikov, A. and Novakov, I. (2018) Right-Sided Pneumothorax in a Patient with Chronic Obstructive Pulmonary Disease and Tuberculosis-Affected Left Lung: A Case Report. Scripta Scientifica Medica, 50, 9. https://doi.org/10.14748/ssm.v50i3.5226

[47] Fettal, N. and Taleb, A. (2012) Pneumothorax Secondary to Chronic Obstructive Pulmonary Disease. 


\section{Appendix A}

Patient age: ........................... Years

* Patient gender: $\quad$ Male $\square \quad$ Female $\square$

* Patient Nationality: Jordanian $\square \quad$ Non-Jordanian $\square$

* Year of death: $\quad 2014 \square \quad 2015 \square \quad 2016 \square$

* The confirmed diagnosis is: Heart failure $\square \quad$ Sepsis $\square \quad$ COPD $\square$

* What is the previous medical condition (more than one response possible) DM $\square \quad$ HTN $\square \quad$ Neurology disorder $\square$

Renal disorder $\square \quad$ Endocrine disorder $\square$

* The prior area before the patient admitted to ICU is: Hospital wards $\square \quad$ Emergency department $\square \quad$ Other hospitals $\square$

* How manytime the patient admitted to ICU during hospitalization? One time $\square \quad$ two time $\square \quad$ more than $\square$

* The time in hours patient needed in ICU (length of ICU stay) ...........Hours.

* The time in hours patient needed in the hospital before ICU admission (length of hospital stay) ...Hours.

* Had the patient received mechanical ventilation during last ICU admission? Yes $\square \quad$ No $\square \quad$ Unknown $\square$

* Had the patient received systematic antibiotic during last ICU admission? Yes $\square \quad$ No $\square \quad$ Unknown $\square$

* Is the chest tube inserted for the patient during the last ICU admission? Yes $\square \quad$ No $\square \quad$ Unknown $\square$

* Had the patient received an indwelling urethral catheter during last ICU admission? Yes $\square \quad$ No $\square \quad$ Unknown $\square$

* Did the central venous catheter or arterial line inserted during last ICU admission? Yes $\square \quad$ No $\square \quad$ Unknown $\square$

* Had the patient received intravenous fluid resuscitation during last ICU admission? Yes $\square \quad$ No $\square \quad$ Unknown $\square$

* Had the patient received vasopressor drugs (dopamine, noradrenaline, dobutamine...etc) during last ICU admission? Yes $\square \quad$ No $\square \quad$ Unknown $\square$

* Had the patient received other invasive procedure during last ICU admission? No $\square \quad$ Yes $\square$ (write it): 